\title{
REVISÃO SISTEMÁTICA DE ESTUDOS QUALITATIVOS EM RESÍDUOS SÓLIDOS
}

\author{
Gabriel de Pinna Mendez ${ }^{1}$, Claudio Fernando Mahler $^{2}$ e Stella Regina Taquette ${ }^{3}$ \\ ${ }^{1}$ M.Sc., Prof. Adjunto do CEFET-RJ - gabrielpmendez@gmail.com \\ ${ }^{2}$ D.Sc., Prof. Titular da COPPE/UFRJ - cfmahler@gmail.com \\ ${ }^{3}$ D.Sc., Profa. Titular da UERJ - stella.taquette@gmail.com
}

\begin{abstract}
Resumo. O presente trabalho buscou analisar estudos relacionados à gestão de resíduos sólidos desenvolvidos com métodos qualitativos. Foi feita revisão sistemática da literatura publicada entre os anos de 2014 e 2019 nas bases de dados Scielo (Scientific Electronic Library Online), no Porta de Periódicos da CAPES e Web Of Science. Além da busca em periódicos de referência na área de resíduos (Waste Management e Waste Management and Research) por meio dos descritores "Pesquisa Qualitativa" e "Resíduos Sólidos" (Qualitative Research and Solid Waste); "Entrevista", "Resíduos Sólidos" e "Percepção" (Interviews, Solid Waste and Perception). Foram encontrados 598 artigos, sendo que após a aplicação de critérios de seleção descritos no presente artigo, o universo foi reduzido para um total de 42 publicações. Os artigos selecionados foram analisados e categorizados quanto aos aspectos mais relevantes como objetivos do trabalho, amostra utilizada no estudo e principais resultados. Verificou-se que a pesquisa qualitativa é adequada para responder questionamentos no campo de estudos sobre resíduos tais como, a relação entre os resíduos e os problemas de saúde pública, as dificuldades na coleta seletiva e nas demais ações de gerenciamento/tratamento, os impactos ambientais do descarte irregular de resíduos e os problemas na gestão de resíduos especiais.
\end{abstract}

Palavras-chave: Resíduos Sólidos; Pesquisa Qualitativa; Revisão da Literatura.

\section{SYSTEMATIC REVIEW OF QUALITATIVE STUDIES IN SOLID WASTE}

\begin{abstract}
This work intends to analyze studies related to solid waste management developed with qualitative methods. A systematic literature review of the articles published between 2014 and 2019 was made in the Scielo databases (Scientific Electronic Library Online), in the CAPES Journal Portal and Web of Science. In addition to searching for reference journals in the area of waste (Waste Management and Waste Management and Research) through the descriptors "Qualitative Research" and "Solid Waste"; "Interview", "Solid Waste" and "Perception" (Interviews, Solid Waste and Perception) and 598 articles were found, and after applying the selection criteria the universe was reduced to a total of 42 publications. The selected articles were analyzed and categorized according to the most relevant aspects such as work objectives, study sample and main results. Qualitative research has been found to be a viable tool and can be employed on a large scale in waste-related studies. It was also found that many studies that use the term "qualitative research" do not have the necessary methodological rigor to be named. It was found that qualitative research is adequate to answer questions in the field of waste studies such as the relationship between waste and public health problems, difficulties in selective collection and other management $/$ treatment actions, environmental impacts, irregular waste disposal and problems in the management of special waste.
\end{abstract}

Keywords: Solid Waste; Qualitative Research; Literature Review.

\section{INTRODUÇÃO}

Os problemas relacionados aos resíduos são tão antigos quanto a própria humanidade, Assim que a espécie humana, cujo modelo de vida era do tipo caçador-coletor, passou a 
criar os primeiros aglomerados urbanos e posteriormente as primeiras cidades, a geração de lixo se tornou motivo de preocupação, pelos problemas ligados à saúde pública e ao meio ambiente. Por volta de 2500 a.C., na Mesopotâmia, os Sumérios enterravam os detritos que produziam.

Posteriormente, os resíduos eram desenterrados e a matéria orgânica decomposta era utilizada como fertilizante, no cultivo de cereais. Em 500 a.C., foi criado possivelmente o primeiro depósito de lixo, em Atenas, na Grécia. Já no século XV, em plena Idade Média, o lixo acumulado contribuiu para o surgimento de epidemias, como a peste negra, febre tifoide e cólera, que aumentaram o índice de mortes no continente europeu (Grippi, 2006).

A problemática da gestão de resíduos não é apenas uma questão técnica de engenharia, mas envolve também aspectos políticos, econômicos, sociais, culturais, regulatórios e ambientais. (Guerrero et al. 2013). Sendo um problema de dimensões diversas, cresce de importância a busca de diferentes métodos de pesquisa na área de resíduos sólidos, que até o presente, em grande parte se utilizam de métodos quantitativos. No entanto, mais recentemente, o método qualitativo vem se mostrando uma ferramenta eficaz para compreensão de questões que não têm boas respostas apenas através de números.

\subsection{O Método Qualitativo}

O Método Qualitativo possui mais de um século de existência tendo sido proposto inicialmente por pesquisadores das ciências sociais/humanas. Contudo, ao longo do tempo foi sendo empregado em outras áreas, principalmente nas Ciências da Saúde (Pessoa et al., 2017; Taquette \& Borges, 2020).

No final do século XIX, em Heidelberg, Alemanha e no início do século XX, em Chicago, Estados Unidos, nascia uma escola de sociologia que se rebelava radicalmente contra o positivismo, o qual, assumia como verdade apenas o que cabia no método ao invés de privilegiar a captação da realidade humana (Minayo; Sanches, 1983; Demo, 1998).

Nas últimas décadas, outras áreas de conhecimento têm utilizado o método qualitativo em pesquisas, como por exemplo, na medicina, educação, administração, e até nas engenharias. A crescente popularidade dos métodos qualitativos foi acompanhada de uma diversificação das práticas de pesquisa e segundo Poupart et al. (2018), a pesquisa qualitativa é hoje realizada em diferentes contextos institucionais e nos meios mais 
imediatamente associados à intervenção, sendo surpreendente a complexidade das áreas englobadas.

Não há um consenso acerca da definição da Pesquisa Qualitativa. Minayo e Costa (2019) afirmam que as pesquisa qualitativas têm como matéria prima um conjunto de substantivos cujos sentidos se complementam: "experiência, vivência, senso comum e ação. E o movimento que informa qualquer abordagem, se baseia em quatro verbos: escutar, compreender, interpretar e dialetizar". Os referidos autores dividem a pesquisa qualitativa em três etapas de trabalho: a primeira fase, exploratória, a segunda, o trabalho de campo e a terceira a análise do material coletado de forma empírica e documental. A pesquisa qualitativa trabalha num universo de valores, crenças, hábitos, atitudes, representações, opiniões, específicos de indivíduos ou grupos, sendo portando humanista.

O investigador percebe o cenário e as pessoas com uma visão holística, separando as suas próprias crenças, perspectivas ou predisposições. Portanto, ela é utilizada para a compreensão de fenômenos que podem ser caracterizados por um alto grau de complexidade, como é o caso dos problemas relacionados ao trato com os resíduos sólidos.

\section{METODOLOGIA}

Foi realizada uma revisão dos artigos publicados entre os anos de 2014 e 2019 de estudos qualitativos sobre gestão de resíduos sólidos, de acordo com a proposta de Okoli \& Schabram (2010), denominada de "stand-alone literature review1". Seu objetivo é revisar a literatura a partir de oito etapas distintas que de forma resumida são: identificação e objetivos da revisão, definição do protocolo e detalhes da busca, critérios de inclusão e exclusão e apresentação dos resultados.

Adotou-se como base de dados o sistema Scielo (Scientific Electronic Library Online), o Portal de Periódicos da CAPES e o Portal Web Of Science. Além da busca de artigos através dos "Portais de busca" citados, foi realizada a busca também por periódicos (Waste Management e Waste Management and Research).

A partir da busca pelas palavras-chave foi encontrado um total de 598 artigos, sendo que após a leitura dos títulos e/ou dos resumos 439 foram excluídos por não se enquadrarem

${ }^{1}$ Revisão de literatura independente 
nos requisitos mínimos do método qualitativo (311) e os demais (128) por estarem em duplicidade, conforme descrito na Figura 1.

Parte dos 139 artigos restantes foram lidos na íntegra, sendo em outros lidos apenas os resultados e conclusões numa segunda triagem, oque conduziu à exclusão de mais 97 artigos, sendo 95 por não se enquadrarem no escopo da pesquisa e 2 por terem utilizado método quantitativo, ao invés de qualitativo. Ao final, o universo de seleção reduziu-se a 42 artigos.

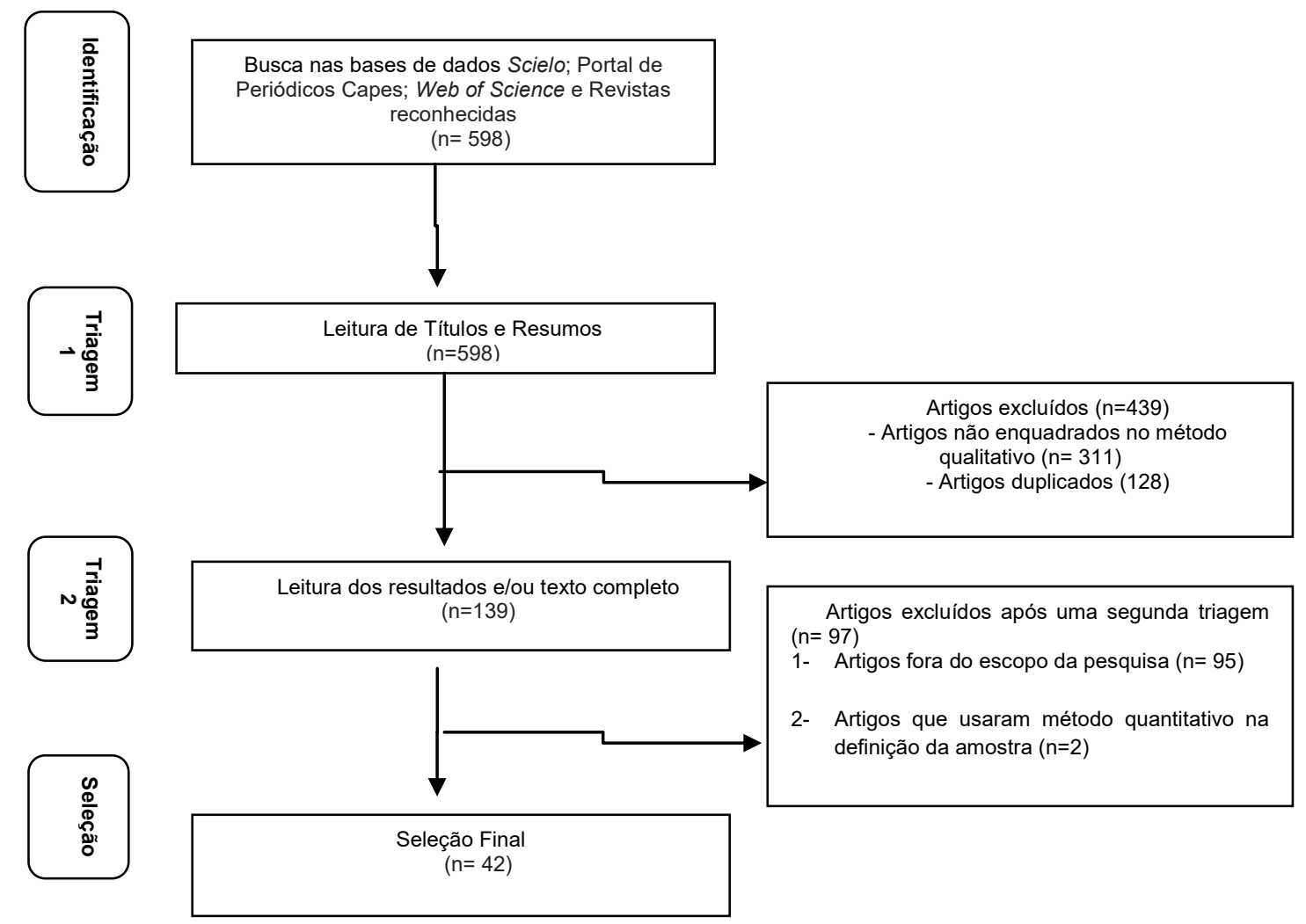

Figura 1. Fluxograma de Seleção dos artigos do Estudo. Fonte: adaptado de Taquette e Maia Monteiro (2019)

\section{RESULTADOS E DISCUSSÕES}

De acordo com o protocolo de seleção descrito na Figura 1, foram selecionados 42 artigos cujo tema se enquadra no escopo da pesquisa. Quanto às principais categorias de problemas de pesquisa abordados nos artigos selecionados, verifica-se que grande parte está relacionado à: coleta seletiva, separação na fonte geradora e atuação dos catadores. Outro número grande de artigos apresentou como problema de pesquisa alguns 
instrumentos e práticas de gestão de resíduos sólidos como logística reversa, coprocessamento e reciclagem, além da gestão dos Resíduos de Serviço de Saúde.

Com relação à utilização de ferramentas do método qualitativo, as mais empregadas foram as entrevistas semiestruturadas e os questionários conforme mostrado no Quadro 3.

Três artigos apresentaram a utilização de softwares para análise de dados qualitativos, sendo estes, respectivamente, o software MAXQDA 10 empregado por Babazadeh et al. (2018), VAPERCOM utilizado por Tomasetto \& Brandalise (2018) e N-VIVO, usado nas pesquisas de Demajorovic et al. (2016). No entanto, cabe salientar que no caso dos questionários a pesquisa qualitativa exige que seja feita uma análise do conteúdo das respostas e não apenas uma tabulação e quantificação dos dados, sob pena de fugir do escopo do método qualitativo.

Dos 42 artigos selecionados, 27 tiveram como quantidade de entrevistados de 2 a 33. Podese afirmar que o critério amostral utilizado na pesquisa qualitativa é uma das questões mais sensíveis e que gera grandes discussões, principalmente quando se procura analisar com parâmetros dos estudos quantitativos, que exigem amostragem estatística representativa.

É importante destacar que o critério de definição da amostra em pesquisa qualitativa não está tomando como requisito principal a quantidade de entrevistados e sim o conteúdo do material coletado. Segundo Minayo (2017, p. 5) "nas pesquisas qualitativas, as amostras não devem ser pensadas por quantidade e nem precisam ser sistemáticas". Mas a sua construção precisa envolver uma série de decisões não sobre quantos indivíduos serão ouvidos, mas sobre a abrangência dos atores sociais, da seleção dos participantes e das condições dessa seleção.

Acerca dos principais resultados encontrados, percebe-se que, de forma geral, a pesquisa qualitativa foi uma ferramenta que deu respostas aos questionamentos dos estudos selecionados.

Por tratar de problemas complexos onde há interação de diversos atores envolvidos, os problemas de gestão dos resíduos envolvem aspectos não apenas técnicos, mas também econômicos, sociais, ambientais e referentes à subjetividade dos seres humanos, de forma que a pesquisa qualitativa é indicada. Os artigos selecionados foram categorizados de acordo com o tema da seguinte forma: 
- categoria I (estudos que tratam dos atores sociais envolvidos na gestão dos resíduos sólidos);

- categoria II (estudos que tratam de ferramentas de gestão de resíduos sólidos);

- categoria III (estudos sobre questões de saúde relacionadas aos resíduos sólidos).

Os Quadros 1, 2 e 3 apresentam os artigos por categorias, apresentando de forma sucinta as informações básicas com autores, ano e local da pesquisa, tema, amostra utilizada e os principais resultados.

Quadro 1. Artigos Selecionados na Categoria 1

\begin{tabular}{|c|c|c|c|}
\hline $\begin{array}{l}\text { Autor - } \\
\text { Ano/Local }\end{array}$ & Assunto/Tema & Amostra & Resultado(s) \\
\hline $\begin{array}{r}\text { 1. Ribeiro \& } \\
\text { Pereira }(2014) \\
\text { Minas Gerais }\end{array}$ & $\begin{array}{l}\text { Conteúdo do discurso dos } \\
\text { atores sociais envolvidos } \\
\text { na gestão de resíduos } \\
\text { sólidos }\end{array}$ & 48 & $\begin{array}{l}\text { Verificou-se nas relações a existência das abordagens } \\
\text { patrimonialista, burocrática, gerencial, social e sistêmica }\end{array}$ \\
\hline $\begin{array}{r}2 . \\
\text { Rodrigues et } \\
\text { al. (2014) } \\
\text { Natal - RN }\end{array}$ & $\begin{array}{l}\text { Postura da sociedade } \\
\text { diante dos resíduos sólidos } \\
\text { urbanos por meio do olhar } \\
\text { do gari }\end{array}$ & 25 & $\begin{array}{l}\text { A população natalense necessita que uma educação } \\
\text { ambiental, melhorando, portanto, a qualidade do meio } \\
\text { ambiente e da vida das pessoas. }\end{array}$ \\
\hline $\begin{array}{r}\text { 3. Moreschi } \\
\text { et al. }(2014) \\
\text { Rio Grande do } \\
\text { Sul }\end{array}$ & $\begin{array}{l}\text { Percepção de integrantes } \\
\text { de instituição de ensino } \\
\text { quanto a separação de } \\
\text { resíduos }\end{array}$ & 33 & $\begin{array}{l}\text { Há a necessidade de formação de profissionais de saúde } \\
\text { qualificados para o manejo adequado destes resíduos. }\end{array}$ \\
\hline $\begin{array}{r}4 . \\
\text { Rodrigues et } \\
\text { al. (2015) } \\
\text { Serra Talhada } \\
-\mathrm{PE} \\
\end{array}$ & $\begin{array}{l}\text { Benefícios sociais e } \\
\text { ambientais da implantação } \\
\text { da Cooperativa de } \\
\text { Reciclagem Resíduos } \\
\text { Sólidos }\end{array}$ & 2 & $\begin{array}{l}\text { O principal objetivo da cooperativa ainda é o social, porém } \\
\text { contribui com a preservação do meio ambiente. }\end{array}$ \\
\hline $\begin{array}{r}\text { 5. Feitosa } \\
\text { et al. }(2015) \\
\text { Iguatu - CE }\end{array}$ & $\begin{array}{l}\text { Percepção dos catadores } \\
\text { de resíduos sobre a } \\
\text { realidade de trabalho }\end{array}$ & 10 & $\begin{array}{l}\text { Observou-se a necessidade do fortalecimento da } \\
\text { organização dos catadores, possibilitando avanço nas } \\
\text { condições de trabalho, vida, renda, valorização do produto e } \\
\text { mercado. }\end{array}$ \\
\hline $\begin{array}{r}\text { 6. Silva et } \\
\text { al. }(2015) \\
\text { Mossoró - RN }\end{array}$ & $\begin{array}{l}\text { Gestão de Resíduos em } \\
\text { assentamento rural }\end{array}$ & 54 & $\begin{array}{l}\text { A falta de coleta e de um tratamento adequado dos resíduos } \\
\text { tem provocado problemas ambientais }\end{array}$ \\
\hline $\begin{array}{r}7 . \\
\text { Ratnapradipa } \\
\text { D. (2015) - } \\
\text { EUA }\end{array}$ & $\begin{array}{l}\text { Percepção da população } \\
\text { quanto aos principais } \\
\text { problemas de saúde } \\
\text { públicas }\end{array}$ & 32 & $\begin{array}{l}\text { Há uma desinformação quanto a gestão dos resíduos ou a } \\
\text { informação somente do que se refere às questões legais, o } \\
\text { que pode levar a uma tomada de decisão ruim quanto às } \\
\text { questões ambientais }\end{array}$ \\
\hline $\begin{array}{r}\text { 8. Valente } \\
\text { et al. }(2016)- \\
\text { Pelotas - RS }\end{array}$ & $\begin{array}{l}\text { Percepção da comunidade } \\
\text { acadêmica sobre a coleta } \\
\text { seletiva no município de } \\
\text { Pelotas }\end{array}$ & 90 & $\begin{array}{l}\text { O poder municipal deve se comunicar mais e melhor com a } \\
\text { população em todas as etapas do gerenciamento dos } \\
\text { resíduos domiciliares do município. }\end{array}$ \\
\hline $\begin{array}{r}\text { 9. Neves et } \\
\text { al. }(2017)- \\
\text { Santa } \\
\text { Catarina }\end{array}$ & $\begin{array}{l}\text { Perfil e Risco à saude dos } \\
\text { catadores de resíduos }\end{array}$ & 39 & $\begin{array}{l}\text { Ações para o desenvolvimento social, econômico e de } \\
\text { melhoria da segurança laboral dos catadores, necessitam } \\
\text { ser implementadas. }\end{array}$ \\
\hline
\end{tabular}




\begin{tabular}{|c|c|c|c|}
\hline $\begin{array}{r}\text { 10. Coelho } \\
\text { et al. (2017)- } \\
\text { Rio Grande do } \\
\text { Sul }\end{array}$ & $\begin{array}{l}\text { Elementos de satisfação e } \\
\text { insatisfação de catadores } \\
\text { de resíduos }\end{array}$ & 11 & $\begin{array}{l}\text { Os elementos de insatisfação são: falta de identificação com } \\
\text { a tarefas e com o conteúdo do trabalho, baixos ganhos } \\
\text { materiais e pessoais obtidos, o preconceito, a } \\
\text { desvalorização e dificuldades nas relações interpessoais. }\end{array}$ \\
\hline $\begin{array}{l}\text { 11. Bento } \\
\text { et al. }(2017) \text { - } \\
\text { Florianópolis }\end{array}$ & $\begin{array}{l}\text { Gerenciamento de } \\
\text { Resíduos dos Serviços de } \\
\text { Saúde }\end{array}$ & 30 & $\begin{array}{l}\text { Os profissionais da instituição investigada conhecem o } \\
\text { Programa de Gerenciamento de Resíduos de Serviço de } \\
\text { Saúde, mas não participam de capacitações sobre o tema. }\end{array}$ \\
\hline $\begin{array}{r}\text { 12. Mahler } \\
\text { e Moura } \\
(2017) \text { - Rio } \\
\text { de Janeiro }\end{array}$ & $\begin{array}{l}\text { Gerenciamento de } \\
\text { Resíduos dos Serviços de } \\
\text { Saúde }\end{array}$ & 3 & $\begin{array}{l}\text { O gerenciamento de RSS tem algumas deficiências o que } \\
\text { eleva consideravelmente o potencial risco dos resíduos dos } \\
\text { serviços de saúde ao meio ambiente e à saúde pública. }\end{array}$ \\
\hline $\begin{array}{r}13 . \\
\text { Hartmann C. } \\
(2017)- \\
\text { Nicarágua }\end{array}$ & $\begin{array}{l}\text { Problemas sociais dos } \\
\text { catadores de resíduos }\end{array}$ & 191 & $\begin{array}{l}\text { Benefícios aos catadores foram desigualmente distribuídos } \\
\text { por bairro, e a coleta informal de resíduos permanece, } \\
\text { contribuindo para a contínua marginalização social, } \\
\text { econômica e degradação ambiental. }\end{array}$ \\
\hline $\begin{array}{l}\text { 14. Borges } \\
\text { et al. }(2017)- \\
\text { Minas Gerais }\end{array}$ & $\begin{array}{l}\text { Avaliação de Plano de } \\
\text { Gerenciamento de } \\
\text { Resíduos de Serviços de } \\
\text { Saúde (PGRSS) }\end{array}$ & 24 & $\begin{array}{l}\text { Os resultados apontam que há grande desconhecimento por } \\
\text { parte dos profissionais do PGRSS. }\end{array}$ \\
\hline $\begin{array}{r}\text { 15. Stumpf } \\
\text { et al. }(2018)- \\
\text { Rio Grande do } \\
\text { Sul }\end{array}$ & $\begin{array}{l}\text { Gestão de resíduos em } \\
\text { quatro empresas do } \\
\text { segmento metalomecânico }\end{array}$ & 4 & $\begin{array}{l}\text { As empresas que possuem sistemas de gestão ambiental } \\
\text { apresentam uma melhor compreensão acerca das suas } \\
\text { responsabilidades ambientais. }\end{array}$ \\
\hline $\begin{array}{r}\text { 16. Coelho } \\
\text { et al. (2017) - } \\
\text { Rio Grande do } \\
\text { Sul }\end{array}$ & $\begin{array}{l}\text { Carga de trabalho dos } \\
\text { catadores de lixo }\end{array}$ & 11 & $\begin{array}{l}\text { Os problemas laborais são: ruídos, exposição a resíduo } \\
\text { químico e biológico, sensação térmica desagradável, } \\
\text { inundações, peso e movimentos repetitivos e desgaste } \\
\text { emocional. }\end{array}$ \\
\hline $\begin{array}{r}17 . \\
\text { Bandeira et al. } \\
(2019)-\text { Rio } \\
\text { Grande do Sul }\end{array}$ & $\begin{array}{l}\text { Gerenciamento de } \\
\text { Resíduos dos Serviços de } \\
\text { Saúde }\end{array}$ & 16 & $\begin{array}{l}\text { Os trabalhadores não executam o descarte correto e } \\
\text { desconhecem a legislação vigente }\end{array}$ \\
\hline $\begin{array}{r}\text { 18. Amate } \\
\text { et al. (2017) } \\
\text { Distrito } \\
\text { Federal }\end{array}$ & $\begin{array}{l}\text { Presença de Resíduos dos } \\
\text { Serviços de Saúde em um } \\
\text { lixão }\end{array}$ & 11 & $\begin{array}{l}\text { Conclui-se que os RS no DF têm uma destinação } \\
\text { inadequada e os catadores constituem um grupo de } \\
\text { pessoas vulneráveis }\end{array}$ \\
\hline $\begin{array}{r}\text { 19. Coelho } \\
\text { et al. (2018) } \\
\text { Santa Maria - } \\
\text { RS }\end{array}$ & $\begin{array}{l}\text { Cargas de Trabalho dos } \\
\text { Catadores de lixo }\end{array}$ & 11 & $\begin{array}{l}\text { Cargas físicas foram associadas a ruídos, exposição a } \\
\text { resíduo químico e biológico, sensação térmica } \\
\text { desagradável, inundações, peso e movimentos repetitivos. }\end{array}$ \\
\hline
\end{tabular}


Quadro 2. Artigos Selecionados na Categoria 2

\begin{tabular}{|c|c|c|c|}
\hline $\begin{array}{c}\text { Autor } \\
\text { Ano/Local }\end{array}$ & Assunto/Tema & Amostra & Resultado(s) \\
\hline $\begin{array}{l}\text { 1. Santos et al. } \\
\text { (2014) Caicó-RN }\end{array}$ & $\begin{array}{l}\text { Acondicionamento de } \\
\text { Resíduos do Serviço de } \\
\text { Saúde - RSS }\end{array}$ & 13 & $\begin{array}{l}\text { As unidades básicas de saúde do município estudado } \\
\text { não possuem Plano de Gerenciamento de Resíduos } \\
\text { do Serviço de Saúde e há problemas no } \\
\text { acondicionamento e em outras fases do } \\
\text { gerenciamento dos resíduos }\end{array}$ \\
\hline $\begin{array}{r}\text { 2. Heber \& Silva } \\
\text { (2014) Aracajú - } \\
\text { SE }\end{array}$ & $\begin{array}{l}\text { Avaliar o processo de } \\
\text { institucionalização da } \\
\text { Política Nacional de } \\
\text { Resíduos (PNRS) }\end{array}$ & 7 & $\begin{array}{l}\text { Há elementos do contexto local que restringem a } \\
\text { realização da política nacional }\end{array}$ \\
\hline $\begin{array}{r}\text { 3. Luna et al. } \\
\text { (2014) Região } \\
\text { Nordeste do Brasil } \\
\end{array}$ & $\begin{array}{l}\text { Logística Reversa de } \\
\text { Garrafas }\end{array}$ & 12 & $\begin{array}{l}\text { Empresas de bebidas possuem grandes desafios para } \\
\text { a consolidação da logística reversa de vasilhames. }\end{array}$ \\
\hline $\begin{array}{r}\text { 4. Ababio (2014) } \\
\text { Accra - República } \\
\text { de Gana - África }\end{array}$ & $\begin{array}{l}\text { Avaliar as condições de } \\
\text { um Aterro de Resíduos }\end{array}$ & 44 & $\begin{array}{l}\text { Os aterros "sanitários" em Accra estão em um estado } \\
\text { de ambivalência devido à má administração, } \\
\text { problemas de projeto e localização de lixões criaram } \\
\text { perturbações estéticas e de odor e aumentaram os } \\
\text { riscos para a saúde. }\end{array}$ \\
\hline $\begin{array}{r}\text { 5. Freitas \& } \\
\text { Nóbrega (2014) } \\
\text { João Pessoa - PB }\end{array}$ & $\begin{array}{l}\text { Benefícios da utilização } \\
\text { de pneus no } \\
\text { coprocessamento de } \\
\text { resíduos em indústria } \\
\text { cimenteira }\end{array}$ & 21 & $\begin{array}{l}\text { A criação de um mecanismo de coleta pela sociedade } \\
\text { possibilitou ganhos econômicos da ordem de R\$ } 2 \\
\text { milhões aos catadores, contribuindo para a melhoria } \\
\text { de sua qualidade de vida. }\end{array}$ \\
\hline $\begin{array}{r}\text { 6. Altoé \& } \\
\text { Voese (2014) } \\
\text { Paraná - Brasil }\end{array}$ & $\begin{array}{l}\text { Gestão sustentável dos } \\
\text { resíduos oriundos da } \\
\text { indústria de biodiesel }\end{array}$ & - & $\begin{array}{l}\text { A gestão de resíduos possibilita a criação de valor na } \\
\text { cadeia de suprimentos do biodiesel. A partir desse } \\
\text { gerenciamento, ocorre a preservação ambiental, a } \\
\text { incidência de multas é reduzida e ainda há } \\
\text { cooperação econômica entre as empresas que } \\
\text { possuem atividades distintas. }\end{array}$ \\
\hline $\begin{array}{r}\text { 7. Almeida } \\
\text { Júnior et al. (2015) } \\
\text { Santa Maria - Rio } \\
\text { Grande do Sul }\end{array}$ & $\begin{array}{l}\text { Avaliação da Coleta } \\
\text { Seletiva }\end{array}$ & 5 & $\begin{array}{l}\text { O processo de coleta seletiva de resíduos proporciona } \\
\text { sustentabilidade às associações e aos moradores, } \\
\text { pois contribui com o meio ambiente e com a melhoria } \\
\text { na qualidade de vida da população }\end{array}$ \\
\hline $\begin{array}{r}\text { 8. Domingos \& } \\
\text { Boeira (2015) } \\
\text { Florianópolis - SC }\end{array}$ & $\begin{array}{l}\text { Gerenciamento de } \\
\text { Resíduos Sólidos } \\
\text { Domiciliares }\end{array}$ & 5 & $\begin{array}{l}\text { Apesar de atender a mais de } 90 \% \text { da população, a } \\
\text { reciclagem é pouco eficiente e há poucas opções para } \\
\text { tratamento e destinação final dos resíduos. }\end{array}$ \\
\hline $\begin{array}{r}\text { 9. Demajorovic } \\
\text { et al. (2016) São } \\
\text { Paulo - SP } \\
\end{array}$ & $\begin{array}{l}\text { Logística Reversa de } \\
\text { Computadores e } \\
\text { Celulares }\end{array}$ & 21 & $\begin{array}{l}\text { O modelo apresentado ameaça à inclusão das } \\
\text { cooperativas de catadores neste processo de LR }\end{array}$ \\
\hline $\begin{array}{r}\text { 10. Netto et al. } \\
\text { (2017) Angra dos } \\
\text { Reis - RJ }\end{array}$ & $\begin{array}{l}\text { Evolução da Coleta } \\
\text { Seletiva no município de } \\
\text { Angra dos Reis/RJ }\end{array}$ & 8 & $\begin{array}{l}\text { Há a necessidade de ações e incentivo do poder } \\
\text { público visando o fortalecimento da coleta seletiva, } \\
\text { maior divulgação e ampliação da abrangência do } \\
\text { programa. }\end{array}$ \\
\hline $\begin{array}{l}\text { 11. Bispo et al. } \\
\text { (2017) Natal - Rio } \\
\text { Grande do Norte }\end{array}$ & $\begin{array}{l}\text { Analisar o sistema da } \\
\text { coleta seletiva municipal }\end{array}$ & 70 & $\begin{array}{l}\text { As cooperativas têm uma estrutura precária que afeta } \\
\text { diretamente o desenvolvimento da atividade e a } \\
\text { qualidade de vida dos catadores envolvidos na cadeia } \\
\text { de reciclagem. }\end{array}$ \\
\hline $\begin{array}{l}\text { 12. Marques et } \\
\text { al. (2017) Belo } \\
\text { Horizonte - MG }\end{array}$ & $\begin{array}{l}\text { Desafios à implantação } \\
\text { da coleta seletiva em } \\
\text { uma instituição de } \\
\text { ensino }\end{array}$ & 22 & $\begin{array}{l}\text { Há a necessidade de investimentos em infraestrutura, } \\
\text { a institucionalização do processo e a promoção } \\
\text { contínua de campanhas de educação ambiental. }\end{array}$ \\
\hline $\begin{array}{l}\text { 13. Kuzma et al. } \\
\text { (2017) Curitiba - } \\
\text { PR }\end{array}$ & $\begin{array}{l}\text { Custos da Gestão de } \\
\text { Resíduos }\end{array}$ & 2 & $\begin{array}{l}\text { As empresas se limitam a cumprir a legislação para o } \\
\text { manejo dos resíduos e os custos apresentam uma } \\
\text { representatividade média pequena, em relação ao } \\
\text { lucro bruto. }\end{array}$ \\
\hline $\begin{array}{r}\text { 14. Tomasetto \& } \\
\text { Brandalise (2018) } \\
\text { Cascavel - PR } \\
\end{array}$ & Ciclo de vida do produto & 40 & $\begin{array}{l}\text { Consumidores possuem percepção ambiental } \\
\text { demonstram preocupação com as etapas do ciclo de } \\
\text { vida do produto do processo produtivo ao descarte. }\end{array}$ \\
\hline
\end{tabular}




\begin{tabular}{|r|l|c|l|}
\hline $\begin{array}{r}\text { 15. Babazadeh } \\
\text { et al. (2018) Tabriz } \\
\text { - Irã }\end{array}$ & $\begin{array}{l}\text { Plano de separação de } \\
\text { resíduos domiciliares } \\
\text { (separação na fonte) }\end{array}$ & 14 & $\begin{array}{l}\text { A separação de resíduos na fonte tem importância na } \\
\text { reciclagem e na gestão de resíduos de toda a cidade }\end{array}$ \\
\hline $\begin{array}{r}\text { 16. Caleffi \& } \\
\text { Marbosa (2018) } \\
\text { Maringá - PR }\end{array}$ & $\begin{array}{l}\text { Gestão } \\
\text { dos Resíduos de }\end{array}$ & $\begin{array}{l}\text { Equipamentos } \\
\text { Eletroeletrônicos }\end{array}$ & $\begin{array}{l}\text { Há deficiencias no fluxo de REEE na cooperative, } \\
\text { dependendo da colaboração dos cidadãos e de } \\
\text { empresas para arrecadação de lixo eletroeletrônico. }\end{array}$ \\
\hline
\end{tabular}

Quadro 3. Artigos Selecionados na Categoria 3

\begin{tabular}{|c|c|c|c|}
\hline $\begin{array}{c}\text { Autor } \\
\text { Ano/Local }\end{array}$ & Assunto/Tema & Amostra & Resultado(s) \\
\hline $\begin{array}{l}\text { 1. El-Wahab et al. } \\
\text { (2014) Alexandria - } \\
\text { Egito }\end{array}$ & $\begin{array}{c}\text { Problemas de saúde de } \\
\text { trabalhadores de empresa de } \\
\text { limpeza pública }\end{array}$ & 346 & $\begin{array}{c}\text { As ações devem concentrar- } \\
\text { se em melhorar e intensificar } \\
\text { as medidas preventivas para } \\
\text { minimizar os níveis de } \\
\text { bioaerossol nas estações de } \\
\text { trabalho, instalando sistemas } \\
\text { de limpeza a vácuo e } \\
\text { transportadores fechados }\end{array}$ \\
\hline $\begin{array}{l}\text { 2. Fontana et al. } \\
\text { (2015) Rio Grande do } \\
\text { Sul }\end{array}$ & $\begin{array}{c}\text { Identificar riscos à saúde referidos } \\
\text { pelos trabalhadores que atuam em } \\
\text { Aterro de Resíduos }\end{array}$ & 24 & $\begin{array}{l}\text { Constatou-se que os sujeitos } \\
\text { não são assistidos nas suas } \\
\text { necessidades, e que o } \\
\text { autocuidado é negligenciado }\end{array}$ \\
\hline $\begin{array}{l}\text { 3. Mahler et al. } \\
\text { (2015) Paracambi - RJ }\end{array}$ & $\begin{array}{l}\text { Condições de saúde dos moradores } \\
\text { do entorno de aterro de resíduos. }\end{array}$ & 40 & $\begin{array}{c}\text { Constatou-se que os } \\
\text { moradores percebem o lixão } \\
\text { como causador de problemas } \\
\text { respiratórios nas crianças } \\
\text { corroborando os dados } \\
\text { epidemiológicos oficiais do } \\
\text { município. }\end{array}$ \\
\hline $\begin{array}{l}\text { 4. Börner et al. } \\
\text { (2015) San Luis Potosi } \\
\text { - México }\end{array}$ & $\begin{array}{l}\text { Riscos na saúde ambiental em } \\
\text { áreas urbanas contaminadas }\end{array}$ & 74 & $\begin{array}{l}\text { Os moradores percebem uma } \\
\text { ampla gama de riscos de } \\
\text { saúde ambientais prejudiciais } \\
\text { ao seu bem-estar, por } \\
\text { exemplo, resíduos, poluição } \\
\text { do ar e falta de higiene. }\end{array}$ \\
\hline $\begin{array}{c}\text { 5. Coelho et al. } \\
\text { (2016) Rio Grande do } \\
\text { Sul } \\
\end{array}$ & $\begin{array}{l}\text { Risco à saúde de catadoras de } \\
\text { recicláveis }\end{array}$ & - & $\begin{array}{c}\text { O desgaste oriundo do } \\
\text { trabalho pode favorecer o } \\
\text { adoecimento das catadoras. }\end{array}$ \\
\hline $\begin{array}{l}\text { 6. Chiariello C. L. } \\
\text { (2018) Porto Mortinho - } \\
\text { MS }\end{array}$ & $\begin{array}{l}\text { Saúde coletiva da população } \\
\text { próxima ao lixão }\end{array}$ & 10 & $\begin{array}{l}\text { Os moradores residentes } \\
\text { próximos ao lixão municipal } \\
\text { não percebem uma boa } \\
\text { gestão dos resíduos por parte } \\
\text { do poder público, pois relatam } \\
\text { a falta de infraestrutura } \\
\text { adequada, condições } \\
\text { insalubres e vulnerabilidade } \\
\text { para contágios de doenças, } \\
\text { tendo em vista a proximidade } \\
\text { do lixão. }\end{array}$ \\
\hline $\begin{array}{l}\text { 7. Ojuri et al. (2018) } \\
\text { Ondo - Nigéria }\end{array}$ & $\begin{array}{l}\text { Risco do lixão Igbatoro, um lixão de } \\
\text { resíduos gerido pelo Estado de } \\
\text { Ondo - Nigéria }\end{array}$ & 110 & $\begin{array}{l}\text { O lixão foi avaliado como nível } \\
\text { de risco moderado. } \\
\text { Questionários distribuídos aos } \\
\text { moradores do entorno também } \\
\text { mostraram que } 83,6 \% \text { dos } \\
\text { entrevistados concordaram } \\
\text { que a atual gestão do aterro } \\
\text { (lixão) é pobre e } 81,8 \% \\
\text { apoiaram sua reabilitação. }\end{array}$ \\
\hline
\end{tabular}


$\mathrm{Na}$ categoria I os estudos qualitativos selecionados evidenciam que os principais atores sociais envolvidos na gestão dos resíduos sólidos são os catadores de matérias que podem ser reaproveitados, as chamadas cooperativas de catadores de materiais recicláveis. Nesses estudos, os principais itens investigados são a percepção dos catadores quanto à carga de trabalho e as dificuldades laborais enfrentadas, os problemas econômicos e sociais e o desempenho de algumas cooperativas.

A percepção de profissionais de instituições de ensino e de estabelecimentos de saúde quanto à gestão de resíduos também foi encontrada na categoria I e em alguns poucos estudos, observa-se como objeto a própria população geradora do resíduo, o que demonstra que o método qualitativo pode ser largamente empregado para estudar a percepção dos atores envolvidos na gestão de resíduos e os catadores ainda são o tema principal da maioria de estudos desse tipo.

$\mathrm{Na}$ segunda categoria, que trata dos estudos acerca das ferramentas de gestão de resíduos sólidos, a coleta seletiva, a reciclagem e a logística reversa foram os temas mais abordados. Outras questões similares como a gestão de Resíduo Eletro Eletrônico, os Planos de Gerenciamento de Resíduos e o ciclo de vida do produto são encontrados.

Todas as ferramentas encontradas na categoria II têm relação direta com as ferramentas mais abordadas (coleta seletiva, reciclagem e logística reversa).

Esses temas, além de serem os que mais aparecem nos artigos selecionados, são temas interdependentes, uma vez que não se pode ter uma logística reversa ou uma reciclagem eficiente, sem uma coleta seletiva bem operada e criteriosa.

$\mathrm{Na}$ terceira e última categoria dos estudos sobre questões de saúde relacionadas aos resíduos sólidos, alguns resultados encontrados mostram a relação entre o contato direto ou indireto com resíduos e problemas de saúde. Chiariello (2018) realizou um estudo com 10 (dez) moradores no entorno de um Lixão em Porto Murtinho - MS através da abordagem qualitativa, utilizando entrevistas semiestruturadas e concluiu que a população local percebe efeitos adversos à saúde pública causada pela proximidade com o lixão.

Segundo Chiariello (2018), com relação às doenças decorrentes da má gestão de resíduos sólidos, " $60 \%$ dos entrevistados apontaram que já contraíram diarreias. 
Não houve casos de doenças como Hepatite B". Em outro estudo, Abadio (2014) verificou a incidência de doenças na população residente nas proximidades de um aterro de resíduos em Gana na África, onde foram relatados surtos de cólera e malária relacionados com a proliferação de vetores e outras condições ruins na operação do aterro.

\section{CONCLUSÕES}

Através da presente revisão, foi possível verificar que a pesquisa qualitativa é indicada para estudos relacionados a resíduos sólidos e pode trazer contribuições para seu manejo. Sugere-se que o ensino do método qualitativo de pesquisa faça parte do escopo de disciplinas ministradas nos Programas de Pós-Graduação.

Por fim, vale salientar as limitações dessa revisão sistemática, pois apesar do uso do termo pesquisa qualitativa como descritor de busca dos artigos ter apresentado uma recorrência grande, em diversos títulos encontrados o escopo da pesquisa não era qualitativo. Pode-se inferir que o método qualitativo tem sido utilizado por autores que ainda não têm conhecimento suficiente sobre o mesmo, tendo como resultado seu uso de forma equivocada. Por outro lado, outros estudos qualitativos podem não ter sido incluídos nessa revisão por não terem sido identificados por estes descritores.

Agradecimentos. $\mathrm{O}$ segundo autor agradece o constante apoio do $\mathrm{CNPq}$ em suas pesquisas. $\mathrm{O}$ segundo e o terceiro autores agradecem o apoio da FAPERJ a seus projetos de pesquisa através da bolsa Cientista do Nosso Estado.

\section{REFERÊNCIAS}

Al-Khatib, I.A. et al. Public perception of hazardousness caused by current trends of municipal solid waste management. Waste Management, v. 36. 2015, p. 323-330.

Babazadeh, T. et al. Challenges in household solid waste separation plan (HSWSP) at source: a qualitative study in Iran. Environment, Development and Sustainability, 2018.

Chiariello, C.L. Políticas de saúde coletiva e gestão urbana de resíduos sólidos na fronteira: um estudo de caso em Porto Murtinho-MS. Revista Videre, v. 10, n. 20, 2018, p. 88-98.

Demajorovic, J.; Augusto, E.E.F.; Souza, M.T.S.de. Logística reversa de reee em países em desenvolvimento: desafios e perspectivas para o modelo brasileiro. Ambiente \& Sociedade, v. 19, n. 2, 2016, p. 119-138

Grippi, S. Lixo: reciclagem e sua história. Rio de Janeiro: Interciencia, 2006. 166p.

Guerrero, L.A.; Mass, G.; Hogland, W. Solid waste management challenges for cities in developing countries. Waste Management, v. 33, 2013, p. 220-232. 
Hartmann, C. Waste picker livelihoods and inclusive neoliberal municipal solid waste management policies: the case of the La Chureca garbage dump site in Managua, Nicaragua. Waste Management, v. 71, 2018, p. 565-577.

Minayo, M.C.S. Amostragem e saturação em pesquisa qualitativa: consensos e controvérsias. Revista Pesquisa Qualitativa, v. 5, n. 7, 2017, p. 01-12.

Minayo, M.C.S.; Costa, A.P. Técnicas que fazem uso da palavra, do olhar e da empatia: pesquisa qualitativa em ação. $1^{\mathrm{a}}$ ed. Aveiro, Portugual: Ludomedia, 2019.

Minayo, M.C.S.; Sanches, O. Quantitativo-qualitativo: oposição ou complementaridade. Cadernos de Saúde Pública, v. 9, n. 3, 1983, p. 237-248.

Oteng-Abadio, M. "Guilty with explanation": rethinking the destiny of landfills in a millennium city in Gana. Management of Envoronmental Quality: An International Journal, v. 25, n. 2, 2014, p. 200-215.

Okoli, C.; Schabram, K. A Guide to Conducting a Systematic Literature Review of Information Systems Research. Sprouts: Working Papers on Information Systems, v. 10, n. 26, 2010.

Pessôa, V.L.S.; Ramires, J.C.L; Ruckert, A.A. (Organizadores). Pesquisa Qualitativa: Aplicações em Geografia. Porto Alegre: Imprensa Livre, 2017. 548p.

Poupart, J. et al. (Orgs.). A pesquisa qualitativa: enfoques epistemológicos e metodológicos. 4.ed. Petrópolis: Vozes, 2018. 464p.

Taquette, S. R.; Borges, L. Pesquisa qualitativa para todos. Petrópolis, Vozes, 2020.

Taquette, S.R.; Monteiro, D., L., M. Causes and consequences of adolescente dating violence: a systematic review. Journal of injury \& violence research, v. 11, n. 2, 2019, p. 137-147.

Tomasetto, S.R.; Brandalise, L.T. Percepção ambiental dos usuários de bandeira em relação ao ciclo de vida do produto. Revista de Gestão Ambiental e Sustentabilidade - GeAS, v. 7, n. 1, 2018, p. 23-42. 